\title{
LA JUSTICIA EN LOS ESTATUTOS DE AUTONOMÍA DE SEGUNDA GENERACIÓN
}

\author{
JOSÉ M. ${ }^{\text {a }}$ PORRAS RAMÍREZ \\ Catedrático de Derecho Constitucional \\ Universidad de Granada
}

\author{
SUMARIO \\ I. El modelo constitucional de referencia \\ y sus desarrollos legales y estatutarios. \\ II. La nueva orientación que surge del \\ ciclo actual de reformas estatutarias. \\ III. Conclusión. Hacia la implantación de \\ un nuevo modelo de articulación de \\ los principios de unidad jurisdiccional \\ y de autonomía política.
}

\section{EL MODELO CONSTITUCIONAL DE REFERENCIA Y SUS DESARROLLOS LEGALES Y ESTATUTARIOS}

Es bien sabido que la Constitución asumió un modelo tradicional de Poder Judicial, reacio a propiciar la adecuación de su organización territorial a la nueva realidad jurídico-política que implicaba la instauración, con todas sus consecuencias, de una forma compuesta de Estado. El suyo es, pues, un modelo que descansa, en sus rasgos esenciales, en principios ajustados a una estructura unitaria o centralizada del mismo ${ }^{1}$. Así se revela, sobre todo, cuando enuncia el principio de unidad jurisdiccional (art. 117.5 CE) como "base de la organización y el funcionamiento de los Tribunales"; cuando señala que los Jueces y Magistrados de carrera "formarán un Cuerpo único", siendo una ley orgánica la que habrá de determinar su estatuto jurídico, así como la

1 En general, acerca del modelo de Poder Judicial adoptado por la Constitución española, vid., L. M. ${ }^{a}$ DÍEZ PICAZO GIMÉNEZ, "Régimen constitucional del Poder Judicial", Madrid, Civitas, 1991, págs. 87 y ss.; y, más recientemente, L. E. DELGADO DEL RINCÓN, "Constitución, Poder Judicial y responsabilidad", Madrid, CEPC, 2002, pássim.

UNED. Teoria y Realidad Constitucional, núm. 24, 2009, pp. 265-292. 
constitución, el funcionamiento y el gobierno de los Juzgados y Tribunales (art. 122.1 CE); cuando crea un Consejo General del Poder Judicial, al que convierte en "órgano de gobierno del mismo" (art. 122.2 CE); y cuando dispone la existencia de un Tribunal Supremo de Justicia, "con jurisdicción en toda España", que es el "órgano jurisdiccional superior en todos los órdenes, salvo lo dispuesto en materia de garantías constitucionales" (art. $123 \mathrm{CE}$ ).

En coherencia con esas determinaciones de principio, la Constitución reitera, en su Título VIII, la "unidad e independencia del Poder Judicial" (art. 152.1.2. "in fine" CE); al tiempo que atribuye al Estado la "competencia exclusiva" sobre la "materia" denominada "Administración de Justicia" (art. 149.1.5. CE). Únicamente, el art. 152.1 CE, en sus párrafos $2 .^{\circ}$ y $3 .^{\circ}$, contiene, a modo de salvedades, referencias a una habilitación competencial hecha a favor de las Comunidades Autónomas, a efectos de que puedan participar en la fijación de las demarcaciones judiciales que hayan de existir en su territorio, si bien "de conformidad con lo previsto en la ley orgánica del poder judicial y dentro de la unidad e independencia de éste»; además de una norma orgánica, que prevé la existencia de Tribunales Superiores de Justicia, culminando la organización judicial en el ámbito territorial de las Comunidades Autónomas cuyos Estatutos hayan sido aprobados por el procedimiento previsto en el artículo 151; y, finalmente, un principio procesal que dispone el fenecimiento de las causas en el ámbito territorial que corresponde a las distintas Comunidades Autónomas. De acuerdo con estas estipulaciones, la Constitución vino a impedir cualquier posibilidad de implantación de una doble jurisdicción, central y autonómica, de manera análoga y simultánea al desdoblamiento que propiciaba en relación con los otros dos poderes tradicionales del Estado ${ }^{2}$. Por ello, ni siquiera el potencial elemento discordante que supuso la previsión de los Tribunales Superiores de Justicia se llegó considerar disfuncional respecto del modelo unitario descrito, al insistir el Tribunal Constitucional, a través de una reiterada jurisprudencia (SSTC 15/1981, 38/1982 y 114/1994), en la plena inserción de aquéllos en la organización judicial del Estado y, por tanto, en su condición ajena a cualquier tentativa de vincularlos a la estructura institucional de las Comunidades Autónomas, en cuyo territorio se encuentran radicados.

No obstante, desde muy pronto, los Estatutos de Autonomía de más pronta elaboración vinieron a enturbiar un panorama aparentemente diáfano, aunque contradictorio con la instauración de un Estado de diseño políticoterritorial complejo, que requiere una articulación más equilibrada de los principios constitucionales de unidad jurisdiccional y de autonomía política ${ }^{3}$. Así, algunas normas institucionales básicas de las Comunidades Autónomas

2 P. LUCAS MURILLO DE LA CUEVA, "El Poder Judicial en el Estado autonómico", en Teoría y Realidad Constitucional, n. ${ }^{\circ}$ 5, 2000, págs. 83-113; en especial, págs. 92 y ss. También, L. LÓPEZ GUERRA, "El Poder Judicial en el Estado de las Autonomías", en VVAA, "Constitución y Poder Judicial. XXV aniversario de la Constitución de 1978", Madrid, Consejo General del Poder Judicial, 2003, págs. 83 y ss.

3 En general, vid., L. JIMENA QUESADA, "El principio de unidad del Poder Judicial y sus peculiaridades autonómicas", Madrid, CEPC, 2000, págs. 66 y ss. 
se adelantaron a las disposiciones de la, aún inexistente, Ley Orgánica del Poder Judicial, determinando la conversión de la competencia estatal exclusiva sobre la "Administración de Justicia", en una competencia compartida. De ese modo sucedió al disponer "cláusulas subrogatorias" ", mediante las cuales las respectivas Comunidades Autónomas asumían el ejercicio de "todas las facultades que la Ley Orgánica del Poder Judicial atribuyera al Gobierno" (art. 18.1 EAC) $)^{5}$. Con ello, tales normas pretendían, al anticipársele, condicionar al legislador orgánico estatal, descartando una interpretación de la competencia del Estado en la materia, según ésta aparece recogida en el art. 149.1.5. ${ }^{\circ} \mathrm{CE}$, como "exclusiva en sentido estricto", esto es, comprensiva de la plenitud de potestades y facultades, normativas y ejecutivas, sobre la administración de Justicia; sino, más bien, como "exclusiva en sentido impropio o amplio", es decir, en la práctica, como una competencia compartida, lo que conlleva la atribución al Estado de la genérica capacidad de ordenación de ese sector de la actividad pública, sin que ello impida a las Comunidades Autónomas desarrollar sus propias facultades al respecto ${ }^{6}$.

No obstante, a falta de un pronunciamiento expreso del Tribunal Constitucional, que determinara el alcance o extensión de la competencia del Estado en la materia, tales normas estatutarias no desapoderaban al legislador estatal para establecer, en su momento, lo que creyera conveniente, en uso de la potestad que la Constitución le confiere, apartándose, en su caso, de lo dispuesto en aquéllas 7 . Y lo cierto es que el mismo hizo un empleo particularmente intenso de sus facultades, en aras de realizar un reparto de las competencias existentes en la materia ${ }^{8}$. Así, al tiempo que confirmaba a esas Comunidades Autónomas algunas de las que se atribuían en sus respectivos Estatutos, sustrayéndoselas así al Estado, tradicional ejercitante de las mismas, le reservaba a éste otras que las normas institucionales básicas de las Comu-

4 Cfr., inicialmente, los arts. 13.1 del Estatuto de Autonomía del País Vasco y 18.1 del Estatuto de Autonomía de Cataluña, ambos de 1979.

5 Como primera aproximación a la cuestión, vid., P. CRUZ VILLALÓN, "La Administración de Justicia en el Estatuto de Andalucía", en VVAA, "El Poder Judicial", Madrid, Dirección General de lo Contencioso del Estado/Instituto de Estudios Fiscales, 1983, Volumen II, págs. 913-943; en especial, pág. 917.

6 El Tribunal Constitucional aludió, por primera vez, a la existencia de este doble concepto de exclusividad competencial, presente en el art. 149.1 CE y también en los Estatutos de Autonomía, en su STC 37/1981. Vid., al respecto, F. BALAGUER CALLEJÓN, "Competencias exclusivas", en F. BALAGUER CALLEJÓN (Coord.), "Reformas estatuarias y distribución de competencias", Sevilla, Instituto Andaluz de Administración Pública, 2007, págs. 19-31.

7 I. DE OTTO Y PARDO, "Organización del Poder Judicial y Comunidades Autónomas", en "Estudios sobre el Poder Judicial", Madrid, Civitas, 1989, págs. 191-216; en especial, págs. 194-195.

8 Acerca de la inserción de la Ley Orgánica del Poder Judicial en el llamado «bloque de la constitucionalidad", lo que la faculta para actuar como parámetro de la constitucionalidad de la

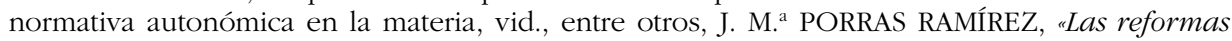
estatutarias y el nuevo sistema autonómico de fuentes del Derecho", Madrid, Civitas, 2007, págs. 51-52. 
nidades Autónomas pretendían asumir? . Para ello el legislador estatal contó con el respaldo expreso del Tribunal Constitucional que, deseoso de consolidar la situación existente, habida cuenta de las expectativas competenciales generadas a favor de las Comunidades Autónomas, llevó a cabo, sobre todo, a través de la STC 56/1990, en palabras de F. Balaguer, una "interpretación estatutaria de la Constitución" ${ }^{10}$ o, como apunta R. Jiménez Asensio, "una interpretación conforme de las cláusulas subrogatorias de los Estatutos de Autonomía con el art. 149.1.5. ${ }^{\circ} \mathrm{CE}^{\prime 11}$ : la cual vino ratificar, en buena medida, la asunción competencial efectuada por los Estatutos de Autonomía, sin contar con lo dispuesto en la, aún inexistente, Ley Orgánica ${ }^{12}$.

Así, movido por el fin indicado, el Tribunal Constitucional trazó una pragmática distinción entre un concepto estricto de "Administración de Justicia", que hizo equivaler, en esencia, a lo que pueda afectar a la función jurisdiccional, consistente en juzgar y hacer ejecutar lo juzgado, además de al gobierno del Poder Judicial; y un concepto amplio, que estimó intercambiable con el de "Administración de Administración de la Justicia", esto es, con cuanto aparece relacionado con los medios, tanto personales como materiales, puestos al servicio del ejercicio de la función jurisdiccional, pero que, dada su condición accesoria e instrumental, ni inciden, en lo fundamental, en ésta, la cual concierne, exclusivamente a los jueces y magistrados, ni al gobierno del Poder Judicial, cometido éste que se reserva a un órgano de relevancia constitucional específico. El deslinde competencial que establece, de esa forma, la Ley Orgánica del Poder Judicial ha permitido que los Ejecutivos de las Comunidades Autónomas, cuyas normas institucionales básicas así lo contemplan, puedan asumir algunas de las competencias que se atribuyen en la materia al Gobierno, las cuales inciden, básicamente, en la gestión del personal no jurisdiccional y en la provisión de los medios materiales necesarios. Sin embargo, el Tribunal Constitucional negó operatividad alguna a esas cláusulas subrogatorias, no sólo cuando entendía que las mismas afectaban al núcleo de la Administración de Justicia en sentido estricto, cuando asumían competencias que la Ley Orgánica atribuía a órganos distintos del Gobierno, o si las mismas dotaban a las Comunidades Autónomas de competencias legislativas, y no sólo ejecutivas y reglamentarias, sino, muy destacadamente, cuando consideró que, mediante dichas cláusulas, aquéllas pretendían asumir

9 Así sucedió, especialmente, tras la importante Reforma de 1994. Cfr., E. ÁLVAREZ CONDE, "El reparto de competencias en materia de Administración de Justicia", en A. MONREAL (ed.), "La división de poderes: el Poder Judicial", Barcelona, ICPS, 1996, págs. 59 y ss. También, R. JIMÉNEZ ASENSIO, "Dos estudios sobre Administración de Justicia y Comunidades Autónomas", Madrid, Civitas, 1998, pássim.

10 F. BALAGUER CALLEJÓN, "Poder Judicial y Comunidades Autónomas", en Revista de Derecho Político, núm. 47, 2000, págs. 53-67; en especial, págs. 55-57.

11 R. JIMÉNEZ ASENSIO, "Reforma de la Administración de Justicia y Comunidades Autónomas", en Parlamento y Constitución, $n .^{\circ}$ 7, 2003, págs. 10 y ss.

12 En general, acerca del significado de las SSTC 56 y 62/1990, vid., J. F. LÓPEZ AGUILAR, "Justicia y Estado autonómico. Orden competencial y Administración de Justicia en el Estado compuesto de la Constitución española de 1978", Madrid, Civitas, 1994, págs. 207 y ss. 
competencias dotadas de una marcada "dimensión supraautonómica", cuestionando así al establecimiento de un estatuto y un régimen jurídico común en todo el Estado para el personal funcionario, integrado en cuerpos nacionales. En esos supuestos, según declaró la STC 105/2000, al interpretar el alcance del art. 455 LOPJ, en aras de salvaguardar el interés supracomunitario o general", en referencia implícita al art. 149.1.1. ${ }^{\circ} \mathrm{CE}$, había que estimar que la competencia le correspondía al Gobierno ${ }^{13}$.

De ese modo, se garantizaba al Ministerio de Justicia la continuidad en el ejercicio de relevantes competencias de gestión, impidiendo así que las Comunidades Autónomas, tal y como era su deseo, y aconsejaba el Libro Blanco de la Justicia de 1997, pudieran desarrollar facultades decisorias en relación con ese personal no jurisdiccional, habida cuenta de la deliberada inserción del mismo en cuerpos nacionales. Por tanto, aunque se permitió que las Comunidades Autónomas asumieran, por medio del oportuno traspaso, la gestión administrativa del personal no jurisdiccional, el Gobierno siguió estando habilitado, al mantenerse el carácter nacional de los cuerpos de funcionarios, para ordenar normativamente, mediante reglamentos, dicho ámbito, adoptando las decisiones fundamentales atinentes al mismo ${ }^{14}$. En consecuencia, a través de la legislación estatal, que refrenda el cuerpo de doctrina conformado, paulatinamente, por el máximo intérprete de la Constitución, se ha venido a determinar la existencia de un núcleo, particularmente amplio, inaccesible a las Comunidades Autónomas, que se ha querido vincular con el art. 149.1.5. ${ }^{\circ}$ CE y demás preceptos constitucionales relacionados, esto es, en esencia, con los arts, 117 y 122 CE. El mismo se resume, en lo esencial, en el ejercicio de la función jurisdiccional, en el gobierno del Poder Judicial y en la fijación de la planta y demarcación de los Juzgados y Tribunales, aun reconociendo, en este último caso, de acuerdo con el art. 152.1.2. ${ }^{\circ} \mathrm{CE}$, si bien "de conformidad con lo previsto en la ley orgánica del poder judicial", que la convierte, de acuerdo con su art. 35, en una mera capacidad de propuesta, la facultad de las Comunidades Autónomas para establecer en sus Estatutos "los supuestos y las formas de participación de aquéllas en la organización de las demarcaciones judiciales del territorio", pero, en ningún caso, a concurrir en el establecimiento de la planta judicial, que es considerada competencia exclusiva del Estado. Ello ha supuesto, para las que así lo han previsto en sus Estatutos, el reconocimiento del derecho a participar, de conformidad con la ley, en la delimitación de las mismas que, teniendo un carácter necesariamente infraprovincial, correspondan a los órganos jurisdiccionales asentados

13 Cfr., también, las SSTC 97/2001, 253/2005, 270/2006 y 294/2006. Vid., al respecto, J. HUELÍN MARTÍNEZ DE VELASCO, "La distribución de competencias entre el Estado y las Comunidades Autónomas sobre la "Administración de Justicia" y la "legislación procesal"», en M. E. CASAS BAAMONDE Y M. RODRÍGUEZ-PIÑERO Y BRAVO FERRER (Dirs.), "Comentarios a la Constitución española. XXX aniversario", Madrid, Fundación Wolters Kluwer, 2008, págs. 2292-2298; en especial, págs. 2293-2294.

14 R. JIMÉNEZ ASENSIO, "Dos estudios sobre Administración de Justicia y Comunidades Autónomas", op. cit., págs. 17 y ss. 
en la respectiva Comunidad Autónoma, circunstancia ésta que conlleva la localización, mediante ley, de su capitalidad (STC 56/1990 FJ 26. ${ }^{15}$.

En suma, a través de la técnica de la ley orgánica, se efectúa una distribución competencial notablemente desequilibrada, que valida, aunque sólo en parte, la subrogación autonómica, salvando así, siquiera sea devaluando su efectividad, unas previsiones estatutarias iniciales cuyo alcance y límites se fijan al tiempo. De ese modo, la Ley Orgánica del Poder Judicial se ha encargado de definir todos los aspectos concernientes al modelo de organización territorial y de gestión de la administración de Justicia en España. Ello ha supuesto, tal y como vino a confirmar la Reforma de dicha Ley Orgánica, efectuada en 2003, la fragmentación de las atribuciones ejecutivas y de gestión entre tres instancias de gobierno, a saber, el Consejo General del Poder Judicial, el Ministerio de Justicia y los Ejecutivos autonómicos, de acuerdo con un complejo esquema de reparto, no siempre racional, que, en sus líneas generales, a pesar de los avances experimentados, confirma el modelo unitario y centralizado aún existente, heredado del pasado. El mismo impide a las Comunidades Autónomas desarrollar una participación más destacada en su configuración, al quedar reducidas al ejercicio de competencias más bien residuales, que afectan únicamente a la gestión de los medios materiales y del personal laboral, a manifestar sus propuestas cuando el Estado determine las demarcaciones judiciales de su territorio y al despliegue de algunas atribuciones de alcance menor, referidas a la formación de los funcionarios judiciales.

La incompleta adecuación de ese modelo a la realidad, hoy firmemente asentada, del Estado autonómico en España, no sólo ha creado disfunciones, habida cuenta del carácter más bien marginal de las competencias autonómicas en la materia, sino que ha frustrado las expectativas suscitadas, motivando que haya llegado a cuestionarse, "de Constitutione ferenda" el mantenimiento de un Poder Judicial único para el Estado y las Comunidades Autónomas ${ }^{16}$. No obstante, la conciencia de las, a día de hoy, insalvables dificultades políticas que supone promover la reforma de la Constitución en un punto como éste, a fin de que la misma habilite abiertamente una configuración dual y coordinada del Poder Judicial, de manera acorde con la pluralidad de ordenamientos existentes y la consiguiente racionalidad inspiradora de un Estado territorialmente compuesto, de rasgos material y tendencialmente federales, ha conducido, una vez más, a que sean los nuevos Estatutos de Autonomía

15 Acerca de esta cuestión, comentan la jurisprudencia del Tribunal Constitucional, A. J. TRUJILLO PÉREZ y M. ${ }^{\mathrm{A}}$ M. NAVAS SÁNCHEZ, "Administración de Justicia", en F. BALAGUER CALLEJÓN (Dir.), "Reformas estatutarias y distribución de competencias", op. cit., págs. 257-281; en especial, pág. 271.

16 F. BALAGUER CALLEJÓN "Poder Judicial y Comunidades Autónomas”, op. cit., págs. 65-66. En contra, E. VÍRGALA FORURIA, "El Poder Judicial en las Comunidades Autónomas", en J. L. IBARRA ROBLES, M. A. GARCÍA HERRERA (dirs.), "Poder Judicial y unidad jurisdiccional en el Estado autonómico", Madrid, Consejo General del Poder Judicial, 2006, págs. 399-447; en especial, págs. 411-413. 
los que tomen la iniciativa a este respecto, habida cuenta de la escasa voluntad demostrada, en ese sentido, por el legislador estata ${ }^{17}$. De ese modo, como se comprobará, los nuevos Estatutos elaborados durante la VIII Legislatura (2004-2008), han pretendido, con variable intensidad, ahondar en las posibilidades que aquél modelo constitucional, a su juicio, les ofrece, en aras de alcanzar un mejor ajuste del Poder Judicial a la forma compuesta de Estado vigente. Así ha sucedido, aun a sabiendas de que las determinaciones que aquéllos introducen, para resultar eficaces, deberán concordar con lo que establezca, en su momento, la Ley Orgánica del Poder Judicial, de acuerdo con la Constitución, al ser dicha norma, y no el Estatuto de Autonomía, la encargada de fijar el marco en el que las Comunidades Autónomas pueden desarrollar las competencias asumidas a través de sus Estatutos (SSTC 56/1990 y 62/1990).

Fundamentalmente, esa reacción estatutaria viene provocada por la negativa de la Ley Orgánica del Poder Judicial, sucesivamente modificada, a dar respuesta a las principales demandas autonómicas en la materia, consistentes, básicamente, en: a) reforzar la posición de los Tribunales Superiores de Justicia, alterando el sistema de recursos existente; b) lograr la territorialización de los órganos de gobierno del Poder Judicial, instituyendo los Consejos de Justicia autonómicos; c) otorgar un mayor protagonismo a las Comunidades Autónomas en la determinación de la organización y planta de los tribunales, así como en la creación de órganos judiciales; d) adaptar el estatuto de los jueces y magistrados a la organización autonómica del Estado; y e) reconocer a las Comunidades Autónomas mayores espacios de intervención en el ámbito de la ordenación y gestión del personal al servicio de la administración de Justicia, sustrayéndolos así de la habitual tutela del Gobierno.

\section{LA NUEVA ORIENTACIÓN QUE SURGE DEL CICLO ACTUAL DE REFORMAS ESTATUTARIAS}

\section{II.1. El Reforzamiento de los Tribunales Superiores de Justicia}

Los Estatutos de Autonomía, parcial o totalmente modificados durante el período 2004-2008, a saber, los de la Comunidad Valenciana, Cataluña, Andalucía, Illes Balears, Aragón y Castilla y León, dedican una atención destacada a aquellas cuestiones referidas al Poder Judicial que afectan a su respectiva Comunidad Autónoma. De ahí que la mayoría de ellos inicie sus referencias a la materia, aludiendo a la necesidad de realzar la posición que ocupa el Tribunal Superior de Justicia asentado en su territorio en la organización judicial del Estado. De ese modo, los Estatutos revelan el "interés legítimo"

17 En general, vid., L. AGUIAR DE LUQUE, A. PREGO DE Oliver TOlíVAR,y J. A. XIOL RÍOS, "La Justicia ante la reforma de los Estatutos de Autonomia", Madrid, Centro de Estudios Jurídicos-Thomson Aranzadi, 2005, pássim. 
que tienen las Comunidades Autónomas en la existencia de estos órganos jurisdiccionales ${ }^{18}$. Así, en algunos, como el catalán, el andaluz, el balear y el aragonés (y en las Propuestas de Reforma de los Estatutos de Castilla-La Mancha y Extremadura), la alusión a los mismos no se incluye, ya, como en el pasado, en el título dedicado a la organización institucional de la Comunidad Autónoma, sino, a fin de disipar los equívocos que ello suscitaba, en otro dedicado, específicamente, al Poder Judicial en el ámbito territorial correspondiente a aquélla. Se pone así de manifiesto, además de la conveniencia de su tratamiento diferenciado, en un marco normativo propio, el hecho de que, de acuerdo con una consolidada jurisprudencia constitucional, el Tribunal Superior de Justicia se inserta en la Comunidad Autónoma, obedeciendo su creación, precisamente, a la existencia de ésta, sin la cual el mismo no sería concebible; al tiempo que se muestra como un órgano del Estado, al formar parte del único Poder Judicial que la Constitución contempla (SSTC 25/1981, 38/1982 y $114 / 1994)^{19}$.

En consecuencia, ningún Estatuto de reciente reforma ha llegado a considerar al Tribunal Superior respectivo, expresión de una "justicia derivada de las Comunidades Autónomas". No podría haber sido de otro modo, ya que la Constitución vigente proclama, incondicionalmente, la unidad del Poder Judicial, impidiendo así, de raíz, la eventual multiplicación de poderes judiciales territoriales. De ese modo, los nuevos Estatutos han venido a determinar, de acuerdo con ésta (art. 152.1.2. ${ }^{\circ}$ ), que los Tribunales Superiores de Justicia culminan "la organización judicial en el ámbito de las Comunidades Autónomas", con las que mantienen una relación no orgánica, sino territorial, la cual deriva del lugar de su sede, por lo que sus competencias continúan siéndolo del Poder Judicial, único existente en todo el Estado. No en vano, la Ley Orgánica del Poder Judicial ha ratificado la naturaleza estatal de los mismos, como sus arts. 26, 34, 70 y 71 se encargan de subrayar, al tiempo que ha reconocido su indiscutible dimensión autonómica. Así, ha dispuesto que «el Tribunal Superior de Justicia tomará el nombre de la Comunidad Autónoma y extenderá su jurisdicción al ámbito territorial de ésta" (art. 71 LOPJ). Que los mismos culminen la organización judicial en el ámbito de cada Comunidad Autónoma, sumado al llamamiento, tanto legal como estatutario, que reciben para actuar como efectivos garantes de los respectivos ordenamientos autonómicos, constituyen, sin duda, los dos rasgos característicos que les asisten, explicando su singularidad. De esas dos notas calificativas surgen sus competencias específicas, de las que se hacen eco, con eficacia y alcance dispar, tanto la Ley Orgánica del Poder Judicial, como los nuevos Estatutos de Autonomía ${ }^{20}$.

18 P. CRUZ VILLALÓN, "Las competencias de la Comunidad Autónoma de Andalucía en materia de Administración de Justicia", op. cit., pág. 924.

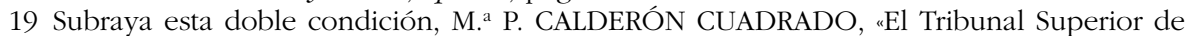
Justicia", en Revista Valenciana d'Estudis Autonòmics, n. ${ }^{\circ}$ 18, 1997, págs. 147-181; en especial, pág. 149.

20 Así, L. LÓPEZ GUERRA, "Estado autonómico y Tribunales Superiores de Justicia", en VVAA, "Estudios de Derecho Constitucional. Homenaje al Prof. D. Joaquín García Morillo", Valen- 
Esa disparidad nace del hecho de que algunos de esos nuevos Estatutos han extraído consecuencias de la definición constitucional que se establece en el art. 152.1.2. ${ }^{\circ}$, que el legislador orgánico estatal no ha deducido, de igual forma, cuando menos hasta el presente. La diversidad de interpretaciones se explica por que la Constitución, si bien dispone la creación de los Tribunales Superiores de Justicia, atribuyéndoles una jurisdicción propia, no ha determinado con precisión cuál es la extensión de la misma. Ha preferido remitirse, a esos efectos, a la ley orgánica, que será quien especifique el alcance de sus competencias. Pero no es la suya una habilitación en blanco, ya que, en aras de ayudar a perfilar su posición, introduce un principio procesal, de necesaria observancia por parte del legislador, que establece el principio del fenecimiento de las causas en el ámbito autonómico. El mismo se vincula al reconocimiento de la condición que poseen los Tribunales Superiores de Justicia de órganos que culminan la organización judicial en el ámbito territorial de las Comunidades Autónomas; y, también, a modo de límite, a la garantía institucional del Tribunal Supremo, considerado "órgano jurisdiccional superior en todos los órdenes, salvo lo dispuesto en materia de garantías constitucionales" (art. $123 \mathrm{CE})^{21}$.

Dicho principio aparece expresado en el art. 152.1.3. ${ }^{\circ} \mathrm{CE}$, que determina: "sin perjuicio de lo dispuesto en el art. 123, las sucesivas instancias procesales, en su caso, se agotarán ante órganos judiciales radicados en el mismo territorio de la Comunidad Autónoma en que esté el órgano competente en primera instancia". De él se han hecho expreso eco, si bien con desigual intensidad, los Estatutos de Autonomía de nueva redacción, algunos de los cuales extraen de ese principio consecuencias que pretenden influir en las disposiciones que tenga a bien adoptar del legislador orgánico estatal, instando a éste a redefinir el sistema de recursos, en particular, y la posición y funciones del Tribunal Supremo y de los propios Tribunales Superiores de Justicia, en general. Tal principio posee una doble inspiración, de índole liberal, primero decantada en el tiempo, ya que entraña, históricamente, un mandato de racionalización del sistema judicial, al propiciar el acercamiento de la Justicia a los ciudadanos 22 ; y federal, después incorporada al mismo, al vincularse a la configuración que ha de recibir el Poder Judicial en un Estado territorialmente compuesto. Así, nutriéndose de ambas perspectivas, dicho principio viene a significar, hoy, que, contra las resoluciones dictadas por los

cia, Tirant lo Blanch, 2001, págs. 459-475; en especial, pág. 467. También, J. F. SÁNCHEZ BARRILAO, "Poder Judicial y unidad jurisdiccional en España", en J. L. IBARRA ROBLES, M. A. GARCÍA HERRERA (Dirs.), "Poder Judicial y unidad jurisdiccional en el Estado autonómico", op. cit., págs. 95-126; en especial, pág. 115-123.

21 Como primera aproximación, cfr., I. DE OTTO Y PARDO, «Los Tribunales Superiores de Justicia”, en "Estudios sobre el Poder Judicial”, op. cit., págs. 217-248; en especial, pág. 229.

22 Esta regla de buena organización judicial arranca en España de la Constitución de Cádiz de 1812, nada proclive al federalismo, cuyo art. 262 dispone: "Todas las causas civiles y criminales fenecerán dentro del territorio de cada Audiencia". De ahí el vínculo histórico existente entre los Tribunales Superiores de Justicia y las Audiencias Territoriales, manifestado en la Disposición Adicional Cuarta de la Constitución. 
juzgados y tribunales radicados en las respectivas Comunidades Autónomas no deberá haber fuera de ellas instancia, esto es, nuevo y pleno examen del asunto, con inclusión de todos los aspectos de hecho y de derecho suscitados. De lo que se desprende que el Tribunal Superior de Justicia se habrá de configurar, en su caso, como la última instancia posible, lo que no significa que el agotamiento de las vías ordinarias de recurso habrá de producirse, necesariamente, y en todo caso, ante el mismo, al poder hacerlo ante un tribunal inferior; o aparecer aquél, en otros supuestos, bien como primera y única instancia; bien no como tal, sino conociendo de recursos extraordinarios ${ }^{23}$.

Así pues, lo único que la Constitución prescribe es la inexistencia de órgano jurisdiccional alguno, jerárquicamente superior al mismo, establecido a tal fin. En todo caso, y haciendo abstracción de los supuestos en los que se prevé la existencia de otros órganos judiciales de instancia, dotados de competencia extendida a todo el Estado, según la organización judicial diseñada con arreglo al principio general de referencia, los recursos que se sustancien ante órganos jurisdiccionales asentados allende la Comunidad Autónoma, sólo podrán ser aquéllos que se consideren extraordinarios, no comportando, en consecuencia, una revisión de los hechos. Los mismos corresponderán, pues, según se deduce de manera indirecta, aunque no necesariamente todos ellos, al Tribunal Supremo, cuya posición se define así de forma negativa. Resulta, de tal modo, que éste, en tanto que "órgano jurisdiccional superior en todos los órdenes, salvo en lo dispuesto en materia de garantías constitucionales" (art. $123 \mathrm{CE}$ ), no puede ser concebido como tribunal de instancia, sino excepcionalmente, esto es, de acuerdo con lo prevenido, a este fin, en los arts. 71.3 y 102.1 CE, en relación con el procesamiento de los Diputados y Senadores, del Presidente y de los demás miembros del Gobierno ${ }^{24}$.

En este sentido, conviene recordar que Tribunal Supremo ha justificado, tradicionalmente, su existencia, que la Constitución y la Ley Orgánica del Poder Judicial aseguran, acudiendo a la técnica de la garantía institucional, al conocer de las diversas modalidades de casación, especialmente por infracción de ley y para la unificación de la doctrina. Ciertamente, de las dos modalidades, la última es la que presenta una mayor trascendencia, al considerarse su función propia e indeclinable, expresando, al tiempo, un límite impuesto por la Constitución al legislador a la hora de configurar la organización judicial. Mediante la misma garantiza y actualiza el principio de unidad jurisdiccional, posibilitando, a su vez, no sólo la realización efectiva del principio de seguridad jurídica (art. 9.3 CE), sino, y lo que es más importante, aún, en el marco de un Estado social y democrático de derecho, del principio de igualdad en la aplicación e interpretación de la ley (art. 14 CE). Tales cometidos, orientados al desarrollo de sus funciones nomofiláctica o de protección de

23 J. M. ${ }^{a}$ PORRAS RAMÍREZ, “Unidad jurisdiccional y autonomía política. La posición de los Tribunales Superiores de Justicia", en Revista Española de Derecho Constitucional, n. ${ }^{\circ}$ 67, 2003, págs. 69-87; en especial, pág. 80.

24 J. M. a PORRAS RAMÍREZ, "Unidad jurisdiccional y autonomía política. La posición de los Tribunales Superiores de Justicia", op. cit., pág. 81. 
la ley, y unificadora o correctora de las desviaciones en la interpretación y aplicación jurisdiccional del derecho, sólo pueden ser desempeñados, dada su peculiar naturaleza, por un tribunal que sea único y superior en todos los órdenes, salvo lo dispuesto en materia de garantías constitucionales (art. 123 CE y 53 LOPJ ${ }^{25}$. Sin embargo, no tiene por qué considerarse privativa del Tribunal Supremo, al poder ostentarla, en su descargo, los Tribunales Superiores de Justicia, fomentando así una más funcional descentralización de algunas de las atribuciones casacionales que aquél viene desempeñando, y que no hay razón para considerar indefectibles al mismo, la competencia que supone conocer de los recursos extraordinarios por infracción de ley, tarea ésta que ha de realizarse ordinariamente en la tramitación y resolución de cualquier recurso, no debiendo desatenderse cuando la decisión judicial no sea susceptible de recurso extraordinario ${ }^{26}$. Y es que no existe óbice constitucional para que los Tribunales Superiores puedan fijar doctrina en todas las materias, tanto si se trata de Derecho estatal, como autonómico, siempre que se reserven al Tribunal Supremo aquellos recursos estimados indispensables para garantizar su función consistente en reconducir a la unidad todo el ordenamiento, en su aplicación por los tribunales ${ }^{27}$.

Esa plenitud competencial de los Tribunales Superiores de Justicia ha sido postulada, explícitamente, de forma paradigmática, por los Estatutos de Cataluña (art. 95.2) y de Andalucía (art. 140.2), aunque, también, de forma implícita, por el de la Comunidad Valenciana (art. 33.2) y el de Aragón (art. 63.2), si bien, en todos lo casos, con remisión expresa a lo que disponga, a este respecto, la Ley Orgánica del Poder Judicial. Es, pues, una determinación que respeta la posición constitucional del Tribunal Supremo, al presuponer que se reserva a éste la competencia "para la unificación de la doctrina", como explícitamente indica, yendo así más lejos que ningún otro, El Estatuto de Cataluña, mediante los procedimientos adecuados, en los recursos en interés de ley o de revisión, cuando exista contradicción entre las sentencias de los Tribunales Superiores de Justicia. De ese modo, se propone restringir la competencia de instancia o en casación ordinaria, atribuida, hasta ahora, al Tribunal Supremo, a aquellos supuestos en que la trascendencia del asunto o la especialidad de la materia así lo justifique: esto es, cuando se trate de cuantías muy

25 Acerca de estos rasgos característicos, cfr., P. SALA SÁNCHEZ, "La labor unificadora del recurso de casación", en VVAA, "El recurso de casación", Barcelona, Consejo General del Poder Judicial, 1994, págs. 11-22. Más recientemente, vid. M. GERPE LANDÍN (Coord.). "La posición del Tribunal Supremo en el Estado Autonómico", Barcelona, Institut d'Estudis Autònomics, 2008, pássim

26 F. GUTIÉRREZ ALVIZ, ARMARIO, V. MORENO CATENA, "Artículo 123: el Tribunal Supremo", en O. ALZAGA VILLAMIL, "Comentarios a la Constitución española de 1978", Madrid, Edersa, Tomo IX, 1999, págs. 521-542; en especial, pág. 532.

27 G. VIDAL ANDREU y otros, "La reforma de la competencia de los Tribunales Superiores de Justicia", en VVAA, "Informe Pi i Sunyer sobre la Justicia en Cataluña", op. cit., 95-149; en especial, pág. 121. También, M. GERPE LANDÍN (Coord.), “Posición y funciones de los Tribunales Superiores de Justicia", Barcelona, Institut d'Estudis Autòmics, 2008, pássim. 
elevadas o cuando concurra la intervención de órganos constitucionales o autoridades del Estado ${ }^{28}$.

Se trata de una aportación muy significativa que contrasta abiertamente con lo dispuesto en los Estatutos elaborados durante la primera etapa del proceso autonómico, los cuales se limitaban a postular, en el mejor de los casos, el principio de especialidad de la casación autonómica, al entender que a los Tribunales Superiores de Justicia sólo se les podía atribuir, como último grado jurisdiccional, el monopolio del examen de los conflictos relacionados con la aplicación de normas de origen autonómico; principio éste que se aplicaba, con todas sus consecuencias, en el ámbito del Derecho civil, respecto de aquellas Comunidades Autónomas dotadas, a tenor de lo dispuesto en el art. 148.1.8. ${ }^{\circ} \mathrm{CE}$, de "derechos civiles, forales o especiales". A ese fin, la técnica utilizada consistía en añadir a la prohibición constitucional de ulteriores instancias extraterritoriales, la interdicción estatutaria de ulteriores grados jurisdiccionales de carácter extraterritorial, en relación con las materias que se consideraban de Derecho autonómico. Dicha opción, habida cuenta de su lógica inspiradora, se asumió en la Ley Orgánica del Poder Judicial (art. 73.1), no suscitando cuestionamiento alguno.

Sin embargo, tal y como se ha indicado, el salto cualitativo se observa en aquellos Estatutos, recientemente aprobados, como, sobre todo, los de Cataluña (art. 95.2) y Andalucía (art. 140.2), que, de forma expresa, han abierto el cauce al reconocimiento del principio de la plena competencia en casación de los Tribunales Superiores de Justicia. Así, los mismos han determinado que el Tribunal Superior de Justicia respectivo habrá de ser considerado la última instancia jurisdiccional de todos los procesos judiciales iniciados en la Comunidad Autónoma, así como de todos los recursos que se tramiten en su ámbito territorial, "sea cual fuere el derecho invocado como aplicable", esto es, ya sea éste estatal o autonómico, si bien "de acuerdo con la Ley Orgánica del Poder Judicial", que "determinará el alcance y contenido de los recursos indicados", "sin perjuicio de la competencia reservada al Tribunal Supremo". Como corolario, los Estatutos catalán y andaluz promueven la competencia del Tribunal Superior de Justicia respectivo para resolver los recursos extraordinarios de revisión que autorice la ley contra las resoluciones firmes dictadas por los órganos judiciales de la Comunidad Autónoma (art. 95.4 EAC y 140.3 EAA); al tiempo que, a su vez, insisten en algo que ya era conocido, esto es, en la competencia exclusiva, que, en todo caso, asiste al Tribunal Superior de Justicia para la unificación de la interpretación del derecho de la Comunidad Autónoma (art. 95.3 EAC y 140.3 EAA), que no la del estatal, ya que este cometido le corresponde, indefectiblemente, "ex Constitutione", al Tribunal Supremo.

28 J. A. XIOL RÍOS, "Artículo 152.1, párrafos 2 y 3: los Tribunales Superiores de Justicia", en M. E. CASAS BAAMONDE y M. RODRÍGUEZ-PIÑERO Y BRAVO FERRER, "Comentarios a la Constitución española. XXX aniversario", Madrid, Fundación Wolters Kluwer, 2008, págs. 25322538 y también, M. FERNÁNDEZ DE FRUTOS, M. GERPE LANDÍN y M. A. CABELLOS ESPIÉRREZ, "El Tribunal Superior de Justicia de Cataluña. Una propuesta de reforma de sus competencias", en Revista Jurídica de Catalunya, n. ${ }^{\circ}$ 3, vol. 104, 2005, págs. 669-698. 
Estimo, por las razones ya expuestas, que, entre otros, dos importantes documentos avalan, como son el Libro Blanco de la Justicia de 1997, elaborado por el Consejo General del Poder Judicial y la "Propuesta de Reforma del Tribunal Supremo en atención a sus funciones constitucionales", redactada por una comisión de magistrados del mismo en 2000, que lo indicado en tales Estatutos en modo alguno resulta disconforme con lo dispuesto en la Constitución. Ahora bien, es claro que no son los Estatutos, sino la Ley Orgánica del Poder Judicial la norma competente para establecer la desconcentración de las facultades casacionales, tradicionalmente asignadas, en régimen de exclusividad, al Tribunal Supremo, a fin de reforzar la posición que ocupan en la organización judicial del Estado los Tribunales Superiores de Justicia autonómicos ${ }^{29}$. Las expresas remisiones que aquéllos realizan a dicha Ley Orgánica así lo ponen, en todo momento, de manifiesto. De ahí que haya que colegir que el propósito que anima a la normativa estatutaria no es otro que influir en el legislador estatal, instándolo a que efectúe, en el marco de la Constitución, de acuerdo con lo indicado, un mejor ajuste del Poder Judicial a la realidad insoslayable del Estado autonómico, hecho éste que debiera redundar en un funcionamiento más racional y eficaz del mismo.

\section{II.2. La terRitorialización del GOBierno del Poder Judicial: la institución de los Consejos de Justicia Autonómicos}

La segunda gran decisión que adoptan los nuevos Estatutos de Autonomía, en orden a promover la mejor adecuación del Poder Judicial a la realidad del Estado compuesto, consiste en la creación de los Consejos de Justicia autonómicos. Dicha decisión, no obstante, se encuentra, también, condicionada a lo que disponga, a este respecto, la Ley Orgánica del Poder Judicial, la cual se beneficia de una reserva, expresamente declarada en los párrafos 2 y 3 del art. 122 de la Constitución, orientada a la garantía, en su dimensión externa, de la independencia judicial. Dicha reserva faculta al legislador orgánico para concretar el estatuto y las funciones, la composición y el mandato del Consejo General del Poder Judicial, en tanto que "órgano de gobierno de mismo". Es claro, pues, tal y como ha reiterado una constante jurisprudencia constitucional, que el gobierno del Poder Judicial se inscribe en el núcleo de la materia "Administración de Justicia", junto con el ejercicio de la función jurisdiccional y la fijación de la planta y demarcación de los Juzgados y Tribunales. De ahí que el mismo quede fuera de la disponibilidad originaria de las Comunidades Autónomas, al vincularse directamente al art.

29 En general, cfr., G. VIDAL ANDREU (Dir.), "Poder Judicial y Estado compuesto: relaciones entre el Tribunal Supremo y los Tribunales Superiores de Justicia", Madrid, 2005, pássim. También, si bien críticamente, Vid. M. ${ }^{a}$ P. GARCÍA RUIZ, "El Tribunal Supremo como mero órgano unificador de la doctrina la posible afectación de su garantía instituconal", en Revista Española de Derecho Constitucional, n. ${ }^{\circ}$ 82, 208, págs. 119-179. 
149.1.5..$^{\circ} \mathrm{CE}$, y se considere competencia exclusiva del Estado, "en sentido propio o estricto", que la desarrollará primordialmente a través de un órgano de relevancia constitucional específico, esto es, por medio del Consejo General del Poder Judicial. En consecuencia, no compete a los Estatutos de Autonomía adoptar al respecto ninguna determinación en sentido distinto del establecido por la Ley Orgánica del Poder Judicial, aspirando a ver reconocida su eficacia inmediata ${ }^{30}$.

No obstante, lo que aquí corresponde analizar no es, ya, la eficacia de esas previsiones autonómicas, que han decidido, unilateralmente, "crear" a los Consejos de Justicia territoriales, sin competencia alguna que les habilite para ello, sino valorar si se ajusta a la Constitución, por razones, en este caso, materiales, una norma orgánica que contemple esos contenidos. Una respuesta favorable podría justificar una actuación, en ese sentido, de la Ley Orgánica del Poder Judicial, que convalidara las estipulaciones estatutarias en la materia. En todo caso, la misma tendría que suponer la configuración, constitucionalmente adecuada, de esos Consejos de Justicia de las Comunidades Autónomas como "órganos territoriales de gobierno del Poder Judicial", lo que implicaría la atribución "ex lege" o delegada a los mismos de competencias cuya titularidad originaria corresponde al Consejo General del Poder Judicial ${ }^{31}$; al tiempo que la remisión a los Estatutos de Autonomía de la facultad de dotar de determinadas funciones a esos órganos territoriales, en relación con el ámbito competencial propio de las respectivas Comunidades Autónomas. Sin embargo, no debe confundirse lo dicho con la posibilidad estatutaria de crear órganos colegiados, a partir de la competencia sobre "organización de sus instituciones de autogobierno" (art. 148.1.1. ${ }^{\circ} \mathrm{CE}$ ), que todas las Comunidades Autónomas poseen, los cuales se dedicarían a desarrollar funciones de asesoramiento, análisis, debate, reflexión e informe, sobre cuestiones o problemas relacionados con la justicia, o de apoyo al ejercicio de competencias propias de la respectiva Comunidad Autónoma en la materia. Y es que estos órganos colegiados, dada su naturaleza exclusivamente autonómica, sólo pueden dedicarse a esos fines, que no al gobierno del Poder Judicial, como ha puesto de manifiesto el Decreto de la Generalitat, 119/2002, de 16 de abril, que instituyó el Consejo de Justicia de Cataluña.

En definitiva, dado que la función de gobierno está constitucionalmente asignada al Consejo General del Poder Judicial, los órganos territoriales que, en su caso, se creen, incidiendo en el ejercicio de esa función, habrán de estar subordinados, de un modo u otro, a aquél, de manera expresa, siendo, en todo caso, la Ley Orgánica del Poder Judicial la que determine su creación

30 Entre otros, vid., J. M. ${ }^{A}$ PORRAS RAMÍREZ, "Fundamento, naturaleza, extensión y límites de la potestad reglamentaria del Consejo General del Poder Judicial", en Revista de Estudios Políticos, n. ${ }^{\circ} 87,1995$, págs. 239 y ss.

31 Así, L. AGUIAR DE LUQUE, "Poder Judicial y reformas estatutarias", en Revista General de Derecho Constitucional, n. ${ }^{\circ} 1$, 2006, págs. 17 y ss. 
y competencias ${ }^{32}$. Esta opción fue la seguida por el Proyecto de Ley Orgánica de Reforma de la Ley Orgánica del Poder Judicial, "en materia de organización de la Administración de Justicia", de 200533, el cual, sin embargo, decayó, al no llegar a aprobarse en Cortes, al finalizar la VIII Legislatura. En dicho Proyecto, en vez de secundarse la propuesta alternativa, formulada en el Libro Blanco de la Justicia, que auspiciaba la potenciación de las Salas de Gobierno de los Tribunales Superiores, trasladando a las mismas un buen número de las atribuciones hasta entonces centralizadas en el Consejo General del Poder Judicial, se prefirió la creación, en cada Comunidad Autónoma, de un Consejo de Justicia. El mismo era, así, concebido como órgano colegiado "ad hoc", destinado a ejercer, de manera desconcentrada y subordinada al Consejo General del Poder Judicial, las funciones de gobierno al efecto previstas en la Ley Orgánica, en detrimento de las Salas de Gobierno de los Tribunales Superiores de Justicia. Además, la tramitación de esta importante modificación de la norma legal, se efectuaba en perfecta sincronía con la reforma de algunos Estatutos de Autonomía, en particular, con el catalán, lo que explica que los mismos concuerden esencialmente. De ahí que la no aprobación del mismo haya dejado a aquéllos privados del sustento que requerían para ver validados sus contenidos. No en vano, la indicada Reforma de la Ley Orgánica protagonizaba un ajuste del gobierno del Poder Judicial al principio autonómico, que, sin duda, podrá cuestionarse en cuanto a su oportunidad o a la valoración que merezca, pero que resulta conforme a la Constitución, dadas las cautelas que, en todo momento, observa. Así, es un hecho cierto que existen unos mismos principios inspiradores de la Reforma indicada y en los nuevos Estatutos, razón por la cual el mismo juicio material que aquélla merece cabe hacer de éstos.

En este sentido, lo primero que en ellos se afirma es el carácter o la naturaleza estatal, que no autonómica, de los Consejos de Justicia, los cuales han de ser concebidos, por tanto, como órganos territoriales subordinados al Consejo General del Poder Judicial. Así, el Estatuto de Cataluña subraya expresamente que, aun considerando su relevante dimensión autonómica, dicho Consejo de Justicia "actúa como órgano desconcentrado del Consejo General Poder Judicial, sin perjuicio de las competencias de este último, de acuerdo con lo previsto en la Ley Orgánica del Poder Judicial" (art. 97). A su vez, en lo que a su composición se refiere, los Estatutos catalán y andaluz han trasladado, con las necesarias adaptaciones, el sistema mixto de elección,

32 En general, vid., M. GERPE LANDÍN, "La configuración constitucional del Consejo General del Poder Judicial", en M. ARAGÓN REYES, J. JIMÉNEZ CAMPO y J. J. SOLOZÁBAL ECHAVARRÍA (eds.), "La democracia constitucional. Estudios en homenaje al Profesor Francisco Rubio Llorente", Madrid, Congreso de los Diputados, Tribunal Constitucional, Universidad Complutense, Fundación Ortega y Gasset, CEP, 2002, Vol. I, págs. 985 y ss.

33 Comenta el alcance de dicha Reforma, en relación con la cuestión que se considera, G. CÁMARA VILLAR, "La "descentralización" del gobierno del Poder Judicial y el Proyecto de Reforma de la LOPJ", en J. L. IBARRA ROBLES, M. A. GARCÍA HERRERA (Dirs.), "Poder Judicial y unidad jurisdiccional en el Estado autonómico", op. cit., págs. 313-338; en especial, págs. 325 y ss. 
que, para los miembros del Consejo General del Poder Judicial, se dispone en la Ley Orgánica, tras su Reforma de 2003, a la espera de que dicha norma, una vez modificada, lo confirme o modifique. De acuerdo con dichos Estatutos, el Consejo de Justicia estará compuesto por el Presidente del Tribunal Superior de Justicia de la Comunidad Autónoma, que lo presidirá, y por los demás miembros natos que se designen según la previsión que contenga la Ley Orgánica del Poder Judicial. Es posible que ello permita la inclusión, si se secunda lo contemplado en la abortada Reforma de 2005, de los Presidentes de las Salas del Tribunal Superior, de los Presidentes de las Audiencias Provinciales, del Fiscal Superior de la Comunidad Autónoma y de los decanos. A su vez, ambos Estatutos añaden como miembros del mismo a los Jueces, Magistrados, Fiscales y juristas de reconocido prestigio que se elijan, correspondiendo al Parlamento autonómico la designación de los miembros del Consejo que determine la Ley Orgánica (arts. 99.1 EAC y 144.2 EAA). Así, a falta de que la misma venga a concretarlo, cabe concebir, por analogía, a menos que se modifique el sistema en aquélla hoy dispuesto, que conformarán, en número igual, un segundo tercio de sus miembros, aquellos Jueces, Magistrados y Fiscales, destinados en la Comunidad Autónoma, que resulten elegidos por los miembros de las Carreras Judicial y Fiscal; estando, finalmente, compuesto un último tercio por los juristas de reconocido prestigio y más de diez años de ejercicio profesional, no pertenecientes a las Carreras Judicial y Fiscal, que elijan las Asambleas legislativas de las Comunidades Autónomas por mayoría de tres quintos.

En cuanto a sus atribuciones, los Consejos de Justicia desempeñarán aquéllas que, inicialmente, la Ley Orgánica del Poder Judicial les reconozca, además de las que les delegue, en su caso, el Pleno del Consejo General del Poder Judicial, circunstancia ésta que conlleva la posibilidad de su revocación. A ellas se unirán las que la Comunidad Autónoma respectiva le asigne, por medio de su Estatuto o de las leyes que elabore su Parlamento, en desarrollo de sus competencias en materia de administración de la administración de Justicia. En cualquier caso, dichas atribuciones las ejercerán los Consejos de Justicia con respecto a los órganos jurisdiccionales situados en el territorio autonómico. Así, las competencias que se desea que ejerzan los Consejos de Justicia, y que sólo los Estatutos catalán y andaluz especifican, coinciden, en buena medida, con aquéllas que, en la actualidad, la Ley Orgánica del Poder Judicial asigna a las Salas de Gobierno de los Tribunales Superiores (art. 152). De ahí que la atribución que los mencionados Estatutos hacen de las mismas a dichos órganos territoriales no sea a costa del Consejo General del Poder Judicial, sino de dichas Salas de Gobierno, redundando en el ejercicio de funciones de informe, consulta y propuesta al Consejo General del Poder Judicial. No se trata, por tanto, de competencias que afecten al núcleo esencial del gobierno del Poder Judicial, las cuales corresponden, en exclusiva, al órgano de relevancia constitucional previsto por la Constitución, sino que, más bien, se trata de competencias de gobierno, manifiestamente delegables o transferibles a esos órganos te- 
rritoriales, de carácter auxiliar, a crear en las Comunidades Autónomas. Las mismas habilitan a los Consejos de Justicia para asumir facultades, hasta ahora centralizadas en el Consejo General del Poder Judicial, en relación con la administración ordinaria del personal judicial, dada su mayor proximidad e inmediatez a su objeto ${ }^{34}$.

Por tanto, según disponen los arts. 98.2 EAC y 144.4 EAA, compete al Consejo de Justicia respectivo: proponer al Consejo General del Poder Judicial los nombramientos y los ceses de los magistrados suplentes y jueces sustitutos; instruir expedientes disciplinarios, de acuerdo con la ley; participar en la planificación de la inspección de juzgados y tribunales; ordenar su inspección y vigilancia, realizando propuestas en este ámbito, además de atender las órdenes de inspección que inste el Gobierno; informar sobre los recursos de alzada contra los acuerdos de las Salas de Gobierno de los juzgados y tribunales de la Comunidad Autónoma; precisar y aplicar en su territorio los reglamentos del Consejo General del Poder Judicial; informar sobre las propuestas de revisión, delimitación y modificación de las demarcaciones judiciales y sobre las propuestas de creación de secciones y juzgados; presentar una memoria anual al Parlamento de la Comunidad Autónoma sobre el estado y el funcionamiento de la administración de Justicia en la misma; y efectuar nombramientos y conceder autorizaciones, licencias y permisos, de acuerdo con los criterios que apruebe el Consejo General del Poder Judicial. A su vez, a las atribuciones expresamente mencionadas se sumarán, según se viene a disponer en cláusula abierta, las demás que atribuyan a los Consejos de Justicia la Ley Orgánica del Poder Judicial, las leyes del Parlamento de la Comunidad Autónoma, de acuerdo con su ámbito competencial propio, y las que le delegue el Consejo General del Poder Judicial. En cualquier caso, es menester nuevamente recordar, que el despliegue de las atribuciones indicadas precisa de la oportuna reforma de la Ley Orgánica del Poder Judicial. En tanto en cuanto dicha modificación no se produzca, las mismas no tendrán más valor que las de meras propuestas, expresivas del "interés autonómico", pero formuladas "de lege ferenda".

De entre todas ellas, la, quizá, más sobresaliente y discutida es la que faculta a dichos Consejos a participar en la designación del Presidente del Tribunal Superior de Justicia, así como en la de los Presidentes de Sala de dicho Tribunal Superior y de los Presidentes de las Audiencias Provinciales (art. 98.2 a) EAC y 144.4 a) EAA). Tan relevante competencia, que implica que el Consejo de Justicia será quien informe sobre los nombramientos discrecionales de los cargos judiciales más relevantes, correspondientes a órganos judiciales radicados en la Comunidad Autónoma, conllevará, si la Ley Orgánica así lo reconoce, siguiendo lo dispuesto en la fallida Reforma de 2005, que, a fin de salvar la competencia que, a este respecto, ha de ejercer en materia de

34 L. LÓPEZ GUERRA, "El Poder Judicial en el ámbito de las autonomías", en VVAA, "Constitución y Poder Judicial. XXV aniversario de la Constitución de 1978", op. cit., págs. 83 y ss. 
nombramientos, indeclinablemente, ex art. 122.2 CE, el Consejo General del Poder Judicial, haya de ser la Comisión de Calificación de éste quien remita al Consejo de Justicia una relación de al menos tres candidatos para cubrir ese puesto, debiendo el Pleno del Consejo General del Poder Judicial motivar su decisión si se aparta del informe que contiene la propuesta remitida por el Consejo de Justicia autonómico ${ }^{35}$. De esa forma, al ser el Consejo General del Poder Judicial quien finalmente decide, se salva la posición jerárquicamente supraordenada que la Constitución le atribuye al mismo en materia de nombramientos judiciales. Al tiempo, se compatibiliza esa insoslayable exigencia constitucional con la intervención autonómica a través del Consejo de Justicia, a quien compete realizar la preceptiva valoración de las capacidades específicas que asisten al candidato propuesto. De ahí que esta atribución hecha a favor de los Consejos de Justicia no afecte a la posición y funciones del Consejo General del Poder Judicial, que se verá únicamente obligado, a la hora de adoptar su decisión, a tener en cuenta la opinión que, sin vincularle, le eleva el órgano de gobierno territorial más cercano al ámbito que se va a ver directamente afectado por aquélla.

Y respecto al funcionamiento y al régimen de los actos del Consejo de Justicia, nuevamente la regulación más completa y, en este sentido, modélica, se halla en el Estatuto de Autonomía de Cataluña. Así, en el mismo se dispone que el Consejo de Justicia se regirá por lo establecido en el reglamento interno de organización y funcionamiento que elabore, de acuerdo con la normativa aplicable (art. 99.2 EAC). Por lo demás, sus actos y resoluciones, que se comunicarán debidamente al Consejo General del Poder Judicial, facilitándole la información que se le requiera (arts. 98.4 EAC y 144.6 EAA), serán recurribles en alzada ante éste, salvo que hayan sido dictados en el ejercicio de competencias de la Comunidad Autónoma, en cuyo caso podrán impugnarse jurisdiccionalmente en los términos establecidos en las leyes (arts. 100 EAC).

En suma, los nuevos Estatutos de Autonomía han previsto la existencia, condicionada a su efectiva creación y dotación de competencias, a través de la Ley Orgánica del Poder Judicial, de los Consejos de Justicia de las respectivas Comunidades Autónomas. Los mismos, a afectos de acomodarse a la Constitución, han sido concebidos como órganos estatales, de ámbito de actuación territorial, desconcentrados del Consejo General del Poder Judicial y a él subordinados. Así, aunque su composición, en parte, la determinen, de manera análoga a su modelo matricial, los Parlamentos autonómicos, se espera que desarrollen las atribuciones que, en esencia, se han venido asignando, hasta el presente, a las Salas de Gobierno de los Tribunales Superiores de Justicia. A ellas se prevé que se añadan las que les encomiende la legislación orgánica competente, las que tenga a bien delegarles el propio Consejo General del Poder Judicial, y las que los propios Estatutos les confieran, al incidir en la esfera de competencias propias

35 G. CÁMARA VILLAR, "La descentralización del gobierno del Poder Judicial...", op. cit., pág. 329. 
de las Comunidades Autónomas. En definitiva, habida cuenta de que su régimen jurídico en modo alguno quiebra la unidad de gobierno del Poder Judicial establecida en la Constitución, sólo queda esperar a que, una vez en funcionamiento, los Consejos de Justicia autonómicos contribuyan, de manera efectiva, a la descentralización de algunas de las funciones que actualmente desarrolla el Consejo General del Poder Judicial, mejorando su eficacia. Más si los mismos, en vez de procurar un mayor acercamiento a las necesidades, demandas y problemas que presenta, a este respecto, cada territorio del Estado, incurren en los bien conocidos vicios que aquejan al funcionamiento de aquél, multiplicándolos, vano y perturbador habrá resultado el esfuerzo.

\section{II.3. LAS COMPETENCIAS AUTONÓMICAS EN MATERIA DE ADMINISTRACIÓN DE JustiCia}

Finalmente, hay que referirse a la regulación que introducen los nuevos Estatutos de Autonomía de las competencias sobre la Administración de Justicia. En este sentido, como se comprobará, las modificaciones que los mismos han incorporado poseen un muy desigual alcance. Así, hay que destacar, una vez más, las sustanciales diferencias que median entre las previsiones estatutarias contenidas, fundamentalmente, en los Estatutos catalán, sobre todo, y andaluz, y el resto de las que se refieren en las normas institucionales básicas, hasta el presente, reformadas ${ }^{36}$.

Inicialmente, cabe indicar que el Estatuto de la Comunidad Valenciana, primero de todos en modificarse, siquiera parcialmente, se limita, en un principio, a reproducir la bien conocida cláusula subrogatoria, de acuerdo con la cual, "corresponde a la Generalitat ejercer, en la Comunidad Valenciana, todas las facultades que la Ley Orgánica del Poder Judicial reconozca o atribuya al Gobierno del Estado" (art. 36.1.1. ${ }^{\circ}$ ). A ello añade, en concreto, la participación de la Generalitat a la hora de "fijar la delimitación de las demarcaciones territoriales de los órganos judiciales en su territorio y la localización de su capitalidad"; y en "la creación o transformación del número de secciones o juzgados en el ámbito de su territorio", en los términos previstos en la Ley Orgánica del Poder Judicial. De ahí que dicho art. 36.1.2. ${ }^{\circ}$ EACV haya de interpretarse en relación con los arts. 35.6 y 36 LOPJ. A su vez, el art. 36.1.3. ${ }^{\circ}$ indica que la Generalitat coadyuvará «en la organización de los tribunales consuetudinarios y tradicionales, en especial, en la del Tribunal de las Aguas de la Vega de Valencia", específicamente reconocido en el art. 19.3 LOPJ; en la provisión "de medios personales, materiales y económicos a la Administración de Justicia" (art. 36.1.4. ${ }^{\circ}$, conforme al art. 37.1 LOPJ) y en la ordenación "de los servicios de justicia gratuita..." (art. 36.1.5. ${ }^{\circ}$, de acuerdo con el

36 Como inicial aproximación, cfr., I. TORRES MURO, "Las competencias autonómicas en materia de Justicia", en Revistsa Española de Derecho Administrativo, n. ${ }^{\circ}$ 139, 2008. 
art. 20 LOPJ). En suma, en vistas de lo indicado, el Estatuto valenciano no alberga novedad significativa o de relieve alguna, en relación a la situación precedente. Como tampoco se desprende ninguna de la lectura de la escueta regulación, prácticamente idéntica, en su tenor literal, que se contiene en el Estatuto balear (art. 98 EAIB).

Por su parte, el Estatuto aragonés se dedica a concretar aquéllas competencias que mejor expresan los intereses de esa Comunidad Autónoma sobre la materia Administración de Justicia, sin que, sin embargo, ello implique, en relación a la mayor parte de las cuestiones tratadas, una ampliación significativa de su esfera de intervención o actuación. Todo lo contrario ocurre, no obstante, con la relevante asunción de «la competencia normativa sobre todo el personal al servicio de la Administración de Justicia no integrado en el Poder Judicial" (art. 67.1 EAA); competencia ésta que, dada la adscripción de dicho personal a Cuerpos Nacionales, queda condicionada a lo que determine la Ley Orgánica del Poder Judicial. Como la misma, hasta el presente (arts. 463 y 470), se ha mostrado reacia a modificar esa situación, determinando que compete al Ministerio de Justicia asumir tal facultad decisoria, sólo promoviendo su reforma, en el sentido indicado, cabrá otorgarle efectividad a esas determinaciones estatutarias. Por lo demás, el Estatuto asume la competencia exclusiva sobre los medios materiales de la Administración de Justicia en Aragón (art. 67.2 EAA); la competencia para acometer la organización, dotación y gestión de las oficinas judiciales y de los órganos y servicios de apoyo a los órganos jurisdiccionales; al tiempo que la competencia para participar, de acuerdo con el Estado, en la gestión de las cuentas de depósitos y consignaciones judiciales y de sus rendimientos (art. 67.3 EAA); y la ordenación y organización de los servicios de justicia gratuita y orientación jurídica gratuita (art. 67.4 EAA), siempre conforme a la Ley Orgánica del Poder Judicial. A su vez, en el marco que ésta determina, el Estatuto aragonés señala que la Comunidad Autónoma participará en la fijación de los límites de las demarcaciones territoriales de los órganos jurisdiccionales, señalando por ley su capital; y en la creación o transformación del número de secciones o juzgados en el ámbito de su territorio (art. 68 EAA). Finalmente, una cláusula subrogatoria atribuye a la Comunidad Autónoma todas las facultades y funciones que la Ley Orgánica del Poder Judicial asigna al Gobierno del Estado con relación a la Administración de Justicia en Aragón (art. 69 EAA).

De forma análoga, el Estatuto castellano-leonés enumera el elenco de competencias que asume la Comunidad Autónoma en relación con la Administración de Justicia en su territorio. Así, dicho Estatuto consolida frente al Estado facultades que se ejercerán, como no podía ser de otro modo, de acuerdo con lo previsto en la Ley Orgánica del Poder Judicial. En ese sentido, ha dispuesto que la Comunidad Autónoma pueda, "en su caso, solicitar la revisión de la planta de los juzgados y tribunales para adaptarla a las necesidades de su ámbito territorial"; "ejercer las facultades normativas, ejecutivas y de gestión que tenga atribuidas en relación con la creación, el diseño y la 
organización de las oficinas judiciales y unidades administrativas, así como respecto al personal no judicial al servicio de la Administración de Justicia"; y «en relación con los organismos e instituciones colaboradoras de aquélla". En fin, aun manifestando, en cláusula abierta, su predisposición a eejercer aquellas otras competencias que le reconozca o atribuya la legislación del Estado", el cometido esencial de la Comunidad Autónoma, en relación con la Administración de Justicia, se cifra en "proveer de medios personales, materiales y económicos a la Administración de Justicia, dentro del marco de sus competencias" y de acuerdo con la Ley Orgánica del Poder Judicial (art. 38 EACL).

Sin embargo, frente a lo estipulado en los Estatutos mencionados, resulta considerablemente más novedoso e intenso el planteamiento que se observa en los Estatutos de Autonomía de Cataluña y de Andalucía. No en vano, los mismos acometen una regulación muy minuciosa de las competencias, en relación con las diferentes submaterias en que se divide la Administración de Justicia. Así se determinan, tanto las facultades que corresponden, en la actualidad, a ambas Comunidades Autónomas, como las que se desea que, en un futuro próximo, asistan a las mismas, una vez que el legislador orgánico estatal así se lo reconozca. De ese modo, la técnica empleada consiste en la realización de un detallado desglose de la materia en cuestión, a los efectos de delimitar claramente el ámbito competencial que corresponde a la Comunidad Autónoma respectiva, limitando con ello la posible incidencia o afectación lesiva por parte del Estado del mismo. Se efectúa así lo que algunos autores han llamado, si bien no del todo correctamente, un «blindaje por descripción", que, en realidad, no es tal, ya que si el Tribunal Constitucional determina que una específica actividad pública es competencia del Estado, la misma no deberá incluirse en el Estatuto de Autonomía, so pena de que dicha cláusula sea declarada, en su caso, inconstitucional. Más si aquél ha resuelto que la misma corresponde a la Comunidad Autónoma, conviene que el Estatuto así la recoja, a fin de impedir que el Estado haga uso de ella, invocando lo dispuesto en la segunda frase del art. 149.3 de la Constitución, en la que, como se recordará, se dispone: "La competencia sobre las materias que no se hayan asumido por los Estatutos de Autonomía corresponderá al Estado...." ${ }^{37}$. A esos efectos, los Estatutos de Cataluña y Andalucía han evitado recurrir a títulos generales, omnicomprensivos, tales como, en este caso, el de "Administración de Justicia", refiriendo a él las competencias, del mismo modo que hacían sus predecesores. Por el contrario, han precisado las facultades específicas que, en relación con los distintos ámbitos o sectores de la materia de referencia, se estiman de competencia autonómica. Dicha técnica se sirve de más de veinticinco años de jurisprudencia del Tribunal Constitucional, a través de la cual se han ido trabajosamente delimitando las

37 C. VÍVER PI-SUNYER, F. BALAGUER CALLEJÓN, J. TAJADURA TEJADA, "La reforma de los Estatutos de Autonomía (con especial referencia al caso de Cataluña)", Madrid, CEPC, 2005, pás$\operatorname{sim}$. 
competencias que, sobre los distintos aspectos o dimensiones de la materia genérica, corresponden, en este caso, a las Comunidades Autónomas. De ahí que los Estatutos catalán y andaluz no hayan hecho, en buena medida, sino recoger, minuciosamente, esa doctrina, de la que se deriva el reconocimiento de las competencias que expresan. Por eso, en ellos la materia "Administración de Justicia" aparece dividida en submaterias, en relación con las cuales se enumeran las competencias, de muy distinto alcance, que ejerce, bien la Generalitat, bien la Junta de Andalucía, de acuerdo con su Estatuto respectivo, en el marco necesario, actual o eventualmente futuro, de la Ley Orgánica del Poder Judicial.

Así, el Estatuto de Andalucía comienza declarando en su art. 145: "La Comunidad Autónoma de Andalucía asume las competencias en materia de Justicia para las que la legislación estatal exija una previsión estatutaria". Esta cláusula viene a insistir en que las competencias que atribuye el Estatuto a la Comunidad Autónoma derivan de una previa habilitación de la ley estatal, operante del reparto de competencias entre el Estado y las Comunidades Autónomas, al tiempo que de la asunción expresa de las mismas efectuada por el propio Estatuto, en orden a evitar que, a falta de ese reconocimiento, según dispone el art. 149.3 de la Constitución, se consideren "competencias residuales del Estado".

En lo demás, los Estatutos catalán y andaluz muestran una idéntica sistemática, al establecer un catálogo de submaterias sobre las que se proyectan competencias autonómicas de desigual intensidad, la mayoría de las cuales no amplían el ámbito competencial de la respectiva Comunidad Autónoma, sino que vienen a consolidarlo, describiéndolo detalladamente; mientras que, en otras ocasiones, en cambio, sí se constata una clara voluntad de incrementar la capacidad de intervención o actuación territorial en el sector de la actividad pública de que se trate. Así, primeramente, ambos Estatutos determinan que corresponderá, ya sea a la Generalitat, ya a la Junta de Andalucía, proponer la convocatoria de oposiciones y concursos para cubrir plazas vacantes de magistrados, jueces y fiscales en la Comunidad Autónoma, al órgano que la ley considere competente (arts. 101.1 EAC y 146.1 EAA). Tras ello encomiendan la convocatoria, novedosamente, al respectivo Consejo de Justicia, si bien a la espera de que el mismo se constituya y resulte, en ese sentido, facultado por la Ley Orgánica del Poder Judicial (arts. 101 EAC y 146 EAA). A lo indicado el Estatuto catalán añade, en el párrafo 3 del mencionado artículo, que las pruebas de los concursos y las oposiciones, "...cuando se celebren en Cataluña, podrán realizarse en cualquiera de las dos lenguas oficiales a elección del candidato". Como esta regulación corresponde, una vez más, originariamente al Estado, conviene matizar lo expresado en dicho precepto, a fin de que la Comunidad Autónoma no disponga unilateralmente algo sobre lo que, a día de hoy, carece de atribución. Más allá de eso, no parece que exista obstáculo constitucional alguno que impida, en su momento, el eventual reconocimiento, efectuado por la Ley Orgánica del Poder Judicial, de esa previsión autonómica. 
Aparte de lo indicado, lo cierto es que la principal diferencia apreciable en la regulación que acometen los Estatutos de Cataluña y Andalucía, afecta a la valoración específica y singular que se contempla en aquél del conocimiento de la lengua y del derecho propio de Cataluña, en las oposiciones y concursos destinados a acceder a plazas vacantes de Magistrados, Jueces, Fiscales y del personal al servicio de la Administración de Justicia en la Comunidad Autónoma. Dicha determinación, justificable y adecuada a la Constitución, en términos generales, se concreta en una remisión estatutaria a la ley, a los efectos de que sea ésta quien determine "la forma y el alcance" en que se hará efectiva la acreditación de "un conocimiento adecuado y suficiente del catalán" "y del derecho propio de Cataluña", "para hacer efectivos los derechos lingüísticos de los ciudadanos" (art. 102.1 y 2. EAC). En cualquier caso, no hay que olvidar que dichas exigencias estatutarias se encuentran condicionadas a lo que disponga, a este respecto, la Ley Orgánica del Poder Judicial y el Estatuto Orgánico del Ministerio Fiscal.

A su vez, destacan las disposiciones que introducen los párrafos 3 y 4 del mencionado artículo, las cuales señalan que para "los concursos de traslado" de los Magistrados, Jueces y Fiscales y para el "personal al servicio de la Administración de Justicia y de la Fiscalía en Cataluña", "se valorará específica y singularmente para obtener una plaza" o se deberá "acreditar... para ejercer las funciones propias de su cargo o puesto de trabajo", respectivamente, "el conocimiento suficiente de la lengua y el derecho propio" y "un conocimiento adecuado y suficiente de las dos lenguas oficiales". Será, no obstante, la mencionada legislación estatal competente la que habrá de precisar el valor a otorgar a dichos méritos

En todo lo demás existe una perfecta concordancia de contenidos entre ambos Estatutos. Así, en cuanto a los medios personales, se establece una novedosa relación de competencias de carácter normativo, correspondientes, tanto a la Generalitat como a la Junta de Andalucía, sobre el personal no judicial al servicio de la Administración de Justicia, de acuerdo con el estatuto jurídico que del mismo establece la Ley Orgánica del Poder Judicial, esencialmente, en su Libro VI (arts. 470-540), que lo vincula a Cuerpos Nacionales. Por tanto, el reconocimiento de dichas competencias normativas requerirá, en su caso, la modificación de la Ley Orgánica, la cual será quien, en su caso, las confirme, atribuyéndoles un alcance estrictamente reglamentario. De todas formas, hay que destacar el hecho de que esa competencia autonómica, de carácter normativo, busca romper con la fragmentación, tantas veces denunciada, de la regulación y gestión del personal no judicial, introduciendo un elemento de racionalidad en la ordenación del sector ${ }^{38}$. Así, de modo exhaustivo, ambos Estatutos indican que las competencias normativas

38 M. GERPE LANDÍN, "La reforma de la Administración de Justicia en España. La necesidad de acomodar la Administración de Justicia al Estado autonómico", en M. A. GARCÍA HERRERA (ed.), "Constitución y democracia. 25 años de Constitución democrática en España", Madrid, Centro de Estudios Políticos y Constitucionales, 2005, vol. II, págs. 425-438; en especial, págs. 435-436. 
que asumen sus respectivas Comunidades Autónomas, en relación con el personal no judicial, afectan a su organización, selección, promoción interna, formación, tanto inicial como continuada, provisión de destinos y ascensos, situaciones administrativas, retribuciones, jornada laboral y horario de trabajo, ordenación de la actividad profesional y funciones, licencias, permisos, vacaciones e incompatibilidades, registro de personal y régimen disciplinario (arts. 103.1 EAC y 147.1 EAA).

Seguidamente, ambos Estatutos atribuyen, respectivamente, a la Generalitat y a la Junta, de acuerdo con la Ley Orgánica del Poder judicial, una serie de competencias ejecutivas y de gestión referidas a ese mismo personal no judicial al servicio de la Administración de Justicia. Las mismas implican: aprobar la oferta de ocupación pública; convocar y resolver los procesos de selección, y adscribir los puestos de trabajo; nombrar a los funcionarios; impartir la formación previa y continuada; elaborar las relaciones de puestos de trabajo; convocar y resolver los procesos de provisión de puestos de trabajo; convocar y resolver los procesos de promoción interna; gestionar el registro de personal, coordinado con el estatal; gestionar ese personal en aplicación de su régimen estatutario y retributivo; ejercer la potestad disciplinaria e imponer las sanciones que procedan; y, en cláusula abierta, ejercer las demás funciones que sean necesarias para garantizar una gestión eficiente de los recursos humanos al servicio de la Administración de Justicia (arts. 103.2 EAC y 147.2 EAA). Por lo demás, ambos Estatutos, en el marco de lo dispuesto en la Ley Orgánica, habilitan al respectivo Parlamento autonómico para que, en su caso, cree cuerpos de funcionarios al servicio de la Administración de Justicia, dependientes de la función pública de la Comunidad Autónoma (arts. 103.3 y $147.3 \mathrm{EAA}$ ). Y, finalmente, ambos, de igual forma, insisten en que, tanto la Generalitat, como la Junta de Andalucía, disponen de competencia exclusiva sobre el personal laboral al servicio de la Administración de Justicia (arts. 103.4 EAC y 147.4 EAA).

En cuanto a los medios materiales, los Estatutos catalán y andaluz detallan, de forma minuciosa, el alcance de sus competencias, a saber, construir y reformar los edificios judiciales y de la fiscalía; proveer de bienes muebles y materiales para las dependencias judiciales y fiscales; configurar, implantar y mantener los sistemas informáticos y de comunicación, sin perjuicio de las competencias de coordinación y homologación que conserva el Estado; gestionar y custodiar los archivos, las piezas de convicción y los efectos intervenidos en lo que no tenga naturaleza jurisdiccional; participar en la gestión de las cuentas de depósitos y consignaciones judiciales y de sus rendimientos, en el marco de lo establecido en la legislación estatal; y gestionar, liquidar y recaudar las tasas judiciales que establezca la Comunidad Autónoma respectiva, en el marco de sus competencias, el cual aparece definido por la Ley Orgánica del Poder Judicial (arts. 104 EAC y 148 EAA).

En relación con la oficina judicial y las instituciones y servicios de apoyo a los órganos jurisdiccionales, ambos Estatutos determinan que, si así lo contempla la Ley Orgánica del Poder Judicial, corresponderá a la Comunidad 
Autónoma su creación, diseño, organización, dotación, y gestión, lo que incluye la regulación de las instituciones, institutos y los servicios de medicina forense y toxicología (arts. 105 EAC y 149 EAA). La reforma de 2009 de la Ley Orgánica del Poder Judicial convalida, en esencia, esas previsiones estatutarias.

A su vez, los dos Estatutos atribuyen al respectivo Ejecutivo autonómico la competencia, que habrá de ser compartida con el Estado, para ordenar y gestionar, se entiende que administrativamente, ex art. 149.1.18. ${ }^{\circ} \mathrm{CE}$, los servicios de justicia y de orientación jurídica gratuita (arts. 106.1 EAC y 150.1 EAA), a los efectos de garantizar el derecho fundamental que reconoce el art. 24, en relación con el $119 \mathrm{CE}$, de acuerdo con lo estipulado en el art. 20 de la Ley Orgánica del Poder Judicial, y en la Ley 1/1996, de 10 de enero, de asistencia jurídica gratuita, norma ésta última que ya venía contemplando, siquiera parcialmente, la competencia autonómica en la materia, en sus arts. 9 y 10. Seguidamente, ambos Estatutos establecen la competencia, en este caso exclusiva, de la Generalitat y de la Junta, respectivamente, para indicar los instrumentos y procedimientos de mediación y conciliación en la resolución de conflictos en las materias de su competencia (arts. 106.2 EAC y 150.2 EAA).

En cuanto a la demarcación, planta y capitalidad judiciales, los Estatutos de Cataluña y Andalucía, una vez más, incluyen disposiciones, de tenor literal idéntico, que habilitan al Gobierno autonómico respectivo para, al menos cada cinco años, previo informe del Consejo de Justicia, proponer al Gobierno del Estado la determinación y la revisión de la demarcación y planta judiciales de la Comunidad Autónoma, a sabiendas de que esa propuesta preceptiva acompañará al proyecto de ley que el Gobierno remita a las Cortes. Se viene así a acoger, con la novedad de la subrogación del Consejo de Justicia en la posición del Consejo General del Poder Judicial, que una reforma de la Ley Orgánica tendrá, en su caso, que convalidar, lo ya dispuesto, a este respecto, en los arts. 29.2 y 35 LOPJ. A ello se añade, en ambos Estatutos, la previsión de que las modificaciones de la planta judicial que no comporten reforma legislativa podrán corresponder al Gobierno de la Comunidad Autónoma, la cual, a su vez, podrá crear Secciones y Juzgados por delegación del Gobierno del Estado, en los términos previstos en la Ley Orgánica del Poder Judicial. Se dispone así una nueva subrogación del Ejecutivo autonómico en el lugar en el que, hasta el presente, la Ley Orgánica sitúa al estatal, según declara su art. 36, lo que requerirá, en su caso, la oportuna modificación de aquélla. Tras ello, ambos Estatutos determinan que la capitalidad de las demarcaciones judiciales será fijada por ley del Parlamento autonómico, como ya venía indicando el art. 35.5 LOPJ (arts. 107 EAC y 151 EAA).

Finalmente, ambos Estatutos contienen referencias a la justicia de pazy de proximidad, acordes con lo determinado en la frustrada Reforma de la Ley Orgánica del Poder Judicial de 2005. Así, atribuyen la competencia sobre la justicia de paz, respectivamente, a la Generalitat o a la Junta de Andalucía, de acuerdo con lo determinado en la Ley Orgánica del Poder Judicial, que será la 
norma que, además, faculte, en su caso, al Consejo de Justicia respectivo para nombrar a los jueces. En todo caso, se dispone que la Comunidad Autónoma se haga cargo de las indemnizaciones, proveyendo los medios necesarios para el ejercicio de sus funciones. Así, creará, también, las secretarías y las proveerá. Por lo demás, viene a indicarse que la Comunidad Autónoma será la responsable, de acuerdo con la Ley Orgánica del Poder Judicial, para instar el establecimiento, en las poblaciones que ésta determine, de un sistema de justicia de proximidad, destinado a la resolución de conflictos menores con celeridad y eficacia (arts. 108 EAC y 152 EAA). Al haber decaído la Reforma de la Ley Orgánica de 2005, que contemplaba similares previsiones, habilitando a las Comunidades Autónomas, en este sentido, los preceptos estatutarios indicados quedan a la espera de una eventual y futura modificación legal, no desplegando, mientras tanto, eficacia alguna.

Para concluir, e independientemente de que el Estatuto andaluz añada dos disposiciones, ausentes en el catalán, alusivas, tanto a la participación popular en la Administración de Justicia, a través de la institución del jurado, de conformidad con la legislación del Estado (arts. 154 EAA, en relación con el 19.2 LOPJ); como al mandato de redacción, por medio de ley, de una carta de derechos de los ciudadanos, que regule su relación con el servicio público de la Administración de Justicia en la Comunidad Autónoma (art. 155 EAA); hay que destacar la nueva cláusula subrogatoria, que establecen los dos Estatutos de referencia, a modo de cierre del título o capítulo respectivo, dedicado al Poder Judicial en la Comunidad Autónoma. Así, en la misma se indica que la Generalitat, en Cataluña, y la Junta, en Andalucía, además de las competencias que expresamente les atribuye su correspondiente Estatuto, ejercerán las funciones y facultades que la Ley Orgánica del Poder Judicial reconozca al Gobierno del Estado con relación a la Administración de Justicia en la Comunidad Autónoma (arts. 109 EAC y 153 EAA).

\section{CONCLUSIÓN. HACIA LA IMPLANTACIÓN DE UN NUEVO MODELO DE ARTICULACIÓN DE LOS PRINCIPIOS DE UNIDAD JURISDICCIONAL Y DE AUTONOMÍA POLÍTICA}

Los nuevos Estatutos elaborados durante la VIII Legislatura (2004-2008) han apostado por la configuración de un modelo de relación entre los principios de unidad jurisdiccional y de autonomía política más equilibrado. De ese modo, si bien con variable intensidad, los mismos ahondan en las posibilidades que dicho modelo, prefigurado en la Constitución, les ofrece, aun a sabiendas de que las determinaciones que introducen, para resultar eficaces, deberán concordar con lo que establezca la Ley Orgánica del Poder Judicial, de acuerdo con la Constitución, al ser dicha norma, y no el Estatuto de Autonomía, la encargada de establecer el marco en el que las Comunidades Autónomas pueden ejercer las competencias asumidas a través de sus respectivos Estatutos. Así, fundamentalmente, esa reacción estatutaria viene 
provocada por las resistencias del legislador estatal a dar respuesta a las principales demandas autonómicas en la materia. De ahí que la misma pretenda influir en aquél en determinados aspectos destacables. Así sucede, en primer lugar, pese a la distinta ambición puesta en el empeño, en relación con la común voluntad, por todos ellos puesta de manifiesto, de realzar la posición que ocupan los Tribunales Superiores de Justicia en la organización judicial del Estado. De ese modo, en particular, los Estatutos catalán y andaluz han instado al legislador orgánico estatal a que redefina el sistema de recursos, en particular, y la posición y funciones del Tribunal Supremo y de los propios Tribunales Superiores de Justicia, en general. Se pretende, de ese modo, que éstos se conviertan en la última instancia jurisdiccional posible de todos los procesos judiciales iniciados en la Comunidad Autónoma y de los recursos que se tramiten en su ámbito territorial. Se aspira así, de acuerdo con la Ley Orgánica del Poder Judicial, a que los mismos puedan fijar doctrina en todas las materias, tanto si se trata de Derecho estatal, como autonómico, aunque se reserven al Tribunal Supremo los recursos estimados indispensables para garantizar su función consistente en reconducir a la unidad todo el ordenamiento, en su aplicación jurisdiccional.

Igualmente, los nuevos Estatutos han previsto la creación de los Consejos de Justicia autonómicos, de forma condicionada, también, a lo que disponga, a este respecto, la Ley Orgánica del Poder Judicial. Dichos Consejos han sido concebidos como órganos estatales de ámbito de actuación territorial, desconcentrados del Consejo General del Poder Judicial y a él expresamente subordinados. Por tanto, según determinan, especialmente, los Estatutos catalán y andaluz, aunque su composición, en parte, la determinen los Parlamentos autonómicos, se espera que desarrollen las atribuciones que, en esencia, se han venido asignando, hasta el presente, a las Salas de Gobierno de los Tribunales Superiores de Justicia. A ellas se prevé que se añadan las que les encomiende la legislación orgánica competente, las que tenga a bien delegarles el propio Consejo General del Poder Judicial, y las que los propios Estatutos les confieran, al incidir en la esfera de competencias propias de las Comunidades Autónomas. En definitiva, habida cuenta de que su régimen jurídico en modo alguno quiebra la unidad de gobierno del Poder Judicial, se espera que, una vez en funcionamiento, contribuyan, de manera efectiva, a la descentralización de algunas de las funciones que actualmente desarrolla el Consejo General del Poder Judicial, mejorando su eficacia.

Y, finalmente, los nuevos Estatutos han regulado, también, con desigual alcance, las competencias que asume su respectiva Comunidad Autónoma sobre la Administración de Justicia, sobresaliendo, nuevamente, las previsiones contenidas en los Estatutos catalán y andaluz, los cuales acometen una regulación muy minuciosa de esas competencias, en relación con las diferentes submaterias en que se divide la Administración de Justicia. Así, en ellos se determinan, tanto las facultades que corresponden en la actualidad a ambas Comunidades Autónomas, como las que se desea que, en un futuro próximo, asistan a las mismas, una vez que el legislador orgánico así se lo reconozca. 
En cualquier caso, las mismas avanzan en la adecuación del Poder Judicial a la realidad del Estado autonómico. Así, particularmente en los dos indicados, sobresale, a fin de romper con la denunciada fragmentación existente entre la ordenación y la gestión del personal no judicial, la novedosa y detallada relación de competencias de carácter normativo que sobre aquél se establecen, aun a sabiendas de que las mismas requerirán, para hacerse efectivas, la modificación, en su caso, de la Ley Orgánica, dada la persistente adscripción de dicho personal a cuerpos nacionales. También, las referencias a las competencias autonómicas, de carácter ejecutivo, acerca de la gestión de dicho personal; las alusivas a los medios materiales; a la oficina judicial y demás instituciones y servicios de apoyo a los órganos jurisdiccionales; a los servicios de justicia y de orientación jurídica gratuita; a la participación autonómica en la determinación de las demarcaciones judiciales y a la creación de secciones y juzgados por delegación del Gobierno; y a las competencias sobre la justicia de paz y proximidad, siempre, en todos estos casos, en los términos que prevea la Ley Orgánica del Poder Judicial, la cual precisará, a fin de concordar con algunas de esas previsiones estatutarias que suponen un ampliación del espacio competencial autonómico, en su caso, de una reforma de calado. Puede que así, logrando una más perfecta articulación de los principios de unidad jurisdiccional y de autonomía política, aun con todas las limitaciones que el modelo constitucional presenta, se propicie, al cabo, un sistema más racional y eficaz, de Administración de Justicia en España.

TITLE: The regulation of Justice in the Statutes of Autonomy of the second generation.

Aвstract: The Statutes of Autonomy of the second generation (2004-2008) defend a more balanced relationship between the constitutional principles of jurisdictional unity and political autonomy. Therefore, besides the different intensity of the regulation they include, all of them profit from the model expressed in the Constitution, although these autonomic rules, to be effective, must be in harmony with the norms contained in the state Organic Law regulating the Judicial Power in Spain. The reason is that this significant Law is entitled by the Constitution to establish the setting in which the Autonomic Communities may exercise the competences assumed in their respective Statutes of Autonomy.

Resumen: Los Estatutos de Autonomía de segunda generación defienden el establecimiento de una más equilibrada relación entre los principios constitucionales de la unidad jurisdiccional y de autonomía política. Así, a pesar de su diferente intensidad reguladora, todos ellos profundizan en las posibilidades que ofrece el modelo prefigurado en la Constitución, a pesar de que estas normas, para ser eficaces, han de estar en armonía con las que se contienen en la Ley Orgánica del Poder Judicial. No en vano esta relevante norma ba sido babilitada por la Constitución para fijar el marco en el que las Comunidades Autónomas pueden ejercer las competencias asumidas en sus respectivos Estatutos.

Key wORDS: Statutes of Autonomy. Constitutional principles of jurisdictional unity and political autonomy. The state Organic Law regulating the Judicial Power.

Palabras clave: Estatutos de Autonomía. Principios constitucionales de unidad judisdiccional y de autonomía política. Ley Orgánica del Poder Judicial. 